\title{
Collaborating for Academic Success: A Tri-Institutional Information Literacy Program for High School Students
}

\author{
KATELYN ANGELL \\ Long Island University, Brooklyn, New York, USA \\ EAMON TEWELL \\ Sarah Lawrence College, Bronxville, New York, USA
}

\begin{abstract}
This article describes a nearly decade-long partnership between three institutions representing school, public, and academic settings in Westchester County, New York. The program, designed to improve the academic performance of local high school students, is unique due to the extensive contact students have with academic librarians during the school year, including two day-long orientations and individual consultation sessions. Using experiences as partners in this collaborative effort, interviews with six teachers and librarians, and the existing literature, this article identifies best practices and key factors for academic libraries that are considering or currently providing instructional and outreach activities to high schools.
\end{abstract}

KEYWORDS partnerships in education, information literacy, library research, outreach programs, high school students, academic libraries, school libraries

Preparing high school students for college is an issue of major importance for academic and school librarians. Higher education institutions and scholars are increasingly engaged with the question of how to improve the firstyear student experience in order to increase retention and graduation rates, and academic librarians, playing a vital role in the student experience, have expressed concern with the preparation of incoming students for years

Received 1 August 2012; accepted 29 October 2012.

Address correspondence to Eamon Tewell, Reference Librarian, Sarah Lawrence College, 
(Jamelske, 2009; Seidman, 2005; Wilcox, Winn, \& Fyvie-Gauld, 2005). Library and Information Science (LIS) researchers and practitioners have long recognized and commented upon deficiencies in first-year student research and information literacy skills when they reach college. Carr and Rockman (2003) note that "the need to increase retention and completion rates for students in higher education is a compelling reason for academic librarians to collaborate with their $\mathrm{K}-12$ colleagues in developing information literacy activities across K-20 education" (p. 52).

Promoting academic success among freshmen is one reason among many for academic librarians to cultivate partnerships with colleagues in school libraries. Effectively imparting information literacy skills to students of all levels remains a foremost concern for K-20 librarians. School and academic librarians alike have embraced information literacy, defined by the Association of College and Research Libraries (ACRL), as "the set of skills needed to find, retrieve, analyze, and use information" (2000, p. 2) to be essential for their students to develop for them to flourish in a world proliferating with countless types and sources of information. Over the past twenty years a number of academic libraries have undertaken collaborative efforts with school and public libraries to improve high school students' college preparation and information literacy skills. Benefits of collaboration between school and academic libraries can include decreased library anxiety, as advocated by Mellon (1986), enhanced visibility of the participating libraries in their communities, and a demonstration of their value as partners in education. It is also suggested that instructional outreach to high schools can assist with recruiting and promote higher education as a whole (Burhanna \& Jensen, 2006; Cosgrove, 2001). As Burhanna and Jensen state, "collaboration can be a powerful pathway to improving student preparation and success across the K-20 educational continuum" (p. 518).

Academic librarians are most likely to come into contact with high school students through requests for conducting orientation sessions for local classes, a scenario typically born of the fact that academic institutions offer more extensive resources than a school library. A high school orientation session could be taken beyond the standard introduction, as it has at Sarah Lawrence College (SLC), and developed into a program that has numerous long-term benefits for all parties involved. Over the program's eight-year duration it has involved participation from the SLC Library, Yonkers High School (YHS), and Yonkers Public Library (YPL). Students enrolled in the YHS International Baccalaureate (IB) Program, a research-intensive college preparatory program, spend their junior and senior years writing selfdirected research papers towards completion of IB requirements. The partnership established between the three institutions is particularly unique in that the students have extensive contact with academic librarians throughout the program. Between a one day-long orientation at YPL, a one day-long introduction to print and online resources at SLC, and research consultation 
sessions conducted with SLC reference librarians, the students receive a great deal of individualized attention and emerge from the program with heightened information literacy skills and college preparedness.

All staff involved in the partnership were interviewed by the authors via e-mail or telephone to gather input on the value of the program and recommendations for institutions interested in developing a similar initiative. Selected quotations from two YHS teachers, the Head of the YPL Reference Department, the Director of Libraries and Academic Computing at SLC, and the former YHS Media Specialist are included throughout this article to provide each individual's valuable perspective on their involvement in this longrunning partnership. A review of the literature related to academic library and high school instructional collaborations will benefit this discussion by providing a context for when and how other institutions have addressed this subject.

\section{LITERATURE REVIEW}

The body of LIS literature contains myriad examples of higher education institutions which have initiated library instruction partnerships with local public schools (Bruch \& Frank, 2011; Zoellner \& Potter, 2010; Collins, 2009; Lee, Morris, Brazell, \& Turner, 2007; Burhanna \& Jensen, 2006; Evans, 1997). These colleges and universities have made it a priority to serve the information needs not only of the campus community but also to expand their expertise and resources to members of the surrounding geographical community. Overall, the primary goal of these partnerships is to improve the information literacy skills of secondary school students, providing them with the research and evaluation techniques necessary for college success. Some of these affiliations include workshops for teachers and school media specialists on resources and services at academic libraries, information which these educators can both integrate into their own practice and relay to their students, further easing their eventual transition into college-level research and coursework (Schein, Conway, Harner, Byerley, \& Harper, 2011; Carlito, 2009; Jackson \& Hansen, 2006). Reiterating the importance of familiarizing teachers and librarians with the academic library at the beginning of a partnership, Evans (1997) comments that "learning what materials were available at the Brooklyn College Library enabled classroom teachers to create assignments that took full advantage of college library access" (p. 90).

Within contemporary LIS research it is highly evident that colleges and universities across the United States are actively and successfully forging connections with local K-12 students. Because the SLC partnership involves high school students, this literature review will similarly focus on articles pertaining to high school populations. Jackson and Hansen (2006) discuss a project in which their institution partnered with school librarians to improve 
the information literacy skills of area middle and high school students. The academic librarians sponsored a workshop in which school librarians were invited to learn about the university library's services and resources. Both parties developed learning objectives targeted at better preparing secondary students for college. Assets of this collaboration included the fostering of close community ties and recruitment for the university in question. However, the overarching success is the enhanced instruction provided to the young patrons:

Students who gain experience utilizing the resources of the academic library will get a head start on the expectations of college research. Finally, regardless of whether students enroll at our university, they will have had positive library experiences which will assist them in their transition from high school to college. (p. 584)

Academic public services librarians are in a special professional and geographical location that allows for the education of community members with resources often financially and/or spatially unavailable to them. By inviting high school students to college campuses for instruction, academic librarians encourage them to get a head start on mastering complex information gathering tools which they will utilize to further themselves and the community.

Such instruction is not always limited to traditional bibliographic instruction. Adeyemon (2009) describes an outreach project which concentrates on academic librarians teaching underserved youth digital literacy and critical thinking skills, including introductions to web design, website evaluation, and cyber-safety. Overall, the aim of this program is to "ensure that marginalized youth populations are introduced to the skills they need for meaningful participation in the digital environment" (p. 86). By helping these students harness the power of emerging technologies, academic librarians are further enhancing the information literacy skills of their communities.

While the majority of the articles in this review detail instruction taught during the school year, there is evidence for fruitful collaborations occurring in the summer. Collins (2009) describes a 20-year relationship between a university library and high school students participating in a summer debate camp. Debaters were given access to the library's computers and took library instruction sessions that utilized active learning techniques such as TurningPoint clickers. This collaboration is only possible with astute and consistent face-to-face and email planning by the Library/Debate Task Force, composed of the Library department heads, the debate coach, and the coach's staff. The Task Force is credited with the program's longevity and continuous improvements:

Because the library and the debate staff are committed to making the workshops enjoyable for the high school students, this group has had a common purpose and that has helped the group to continually strive to make improvements in the workshops. (p. 150) 
This library's experience illustrates the necessity of creating and sustaining a solid and systematic committee to ensure a rewarding partnership for all. Collins provides a detailed explanation of the program's initiation and trajectory, a framework which can be used as a template to explore similar programs at other institutions.

As YHS is located within an urban environment, it is important to address the interplay of academic institutions and community members within this specific geographical location. Acknowledging the infeasibility of uncritically projecting findings of one program onto another, Zoellner and Potter (2010) caution that "the relationship between high school and university library instructional programming and resources in other geographic areas with different demographics and governance structures requires additional study" (p. 198). Carlito (2009) discusses the role of the urban university in the lives of community members, presenting the idea that residents often perceive a university library as a branch of the public library system. This notion is particularly relevant at a time in which public schools perpetually face severe budget crises, negatively impacting the ability of school media specialists to retain appropriate levels of staffing and resources. With public schools and their media centers receiving insufficient funding, students and teachers "will rely more on local public and academic libraries for the students' research needs. This school year, already, we have received more requests for instruction than we did the entire 2007-2008 school year" (p. 45). The university library in question provides an extremely versatile level of instruction to secondary school teachers and students at both locations. In conjunction with teaching standard library resources, these librarians also provide instruction on free web tools such as blogs and wikis, which can be useful to both media specialists and students. To optimally reach community members, the university library staff often attend local public school events to inform teachers, media specialists, and administrators of available services.

In addition to exploring qualitative case study literature, it is instrumental to also investigate studies premised upon survey methodologies. Zoellner and Potter (2010) conducted a study intended to both investigate library services and resources at regional high schools and provide university librarians with information necessary for advancing instruction to high school and first-year college students. High school media specialists surveyed all reported that they were interested in collaborations which surpassed the traditional model of sending students to the university for library instruction, including such ideas as "university librarians presenting at high schools, university students discussing with high school students research expectations at the university, and university librarians holding workshops for high school teachers" (p. 197). Implementation of these suggestions could prove useful to any academic institution either considering or already participating in a partnership with secondary schools as a means of galvanizing student learning outcomes. 
While the SLC/YHS/YPL partnership shares various commonalities with programs explored in the literature review, it is also unique for several reasons. First, the project is composed of a trifecta of community players: an academic library, a public library, and high school students and teachers. Unlike many patrons, who often receive one-shot library instruction sessions, SLC librarians work with YHS students throughout the entire academic year, allowing us regular and highly personalized contact. Additionally, all of the participating students are enrolled in the elite IB program, signifying that they consistently complete academic coursework at a college level. Perusal of LIS databases did not yield any articles which focused primarily on the instruction of IB students by academic librarians, although Carlito (2009) mentions working with both IB and Advanced Placement (AP) students and Tilke (2011) explores strategies and challenges of school librarians serving IB high school patrons.

Occurring during a student's junior and senior years of high school, the

IB Diploma Programme is a

demanding two-year curriculum leading to final examinations and a qualification that is welcomed by leading universities around the world. Each programme includes a curriculum and pedagogy, student assessment appropriate to the age range, professional development for teachers and a process of school authorization and evaluation. ("The IB at a Glance," n.d.)

Due to the heavy intellectual demands of the IB program on the students, access to an academic library combined with a school media center makes for an optimal learning environment. Two media specialists with a history of working with IB students describe the typical responsibilities of the supporting librarians:

Helping the student identify the essential question and subsidiary questions; plan the research strategy; locate and use credible and reliable sources; write annotations for the sources as a technique to extract ideas from the text as well as to compare, contrast, and reject misinformation; and verify data in sources. (Yutzey \& Piazza, 2007, p. 24)

Accomplishment of these tasks, as exemplified by the partnership among SLC, YHS, and YPL, can be divided among multiple community players to guarantee greatest possible acquisition and retention of the research and writing skills required by the challenging IB program. By promoting information literacy and academic success, this partnership remarkably improves the students' transition to college-level research expectations. 
A large urban high school, YHS is currently ranked the fourth best high school in New York state and 24th best high school in the country (U.S. News $\&$ World Report, 2012). Offering the IB program since 2001 (International Baccalaureate, n.d.a), YHS offers its students, 67\% of whom are from an economically disadvantaged background (U.S. News \& World Report, 2012), a free, high-quality education. Those YHS students who opt to enroll in the IB program are well-aware of the advantages this investment holds for their academic and professional future. Reflecting on her experience in the IB program, one YHS senior remarks that the IB program "helps you get into the most prestigious colleges and universities. Academically, the IB program has set me up to successfully compete with students from better-resourced and -funded schools" (Brody, 2012). Despite the strength of the IB program and YHS in general, the lack of media center staff and sophisticated research tools and collections at YHS prompted the high school to reach out to local institutions for reference and instruction assistance.

Established in 2004, the SLC, YHS, and YPL partnership was the brainchild of the YHS media specialist. Conversations with an IB school teacher on methods of better supporting the IB program germinated the idea of collaborating with a local college or university. The media specialist contacted the director of the SLC Library, who instantly welcomed the suggestion. Explaining one of the foremost advantages of the partnership, the media specialist reflected:

In the school library there was only one media specialist for 1800 students-time and resources had to be juggled constantly. Students don't get the same kind of focused attention as they do when they are working with the SLC librarians. (B. Hough, personal communication, May 21, 2012)

In addition to the SLC reference librarians, the central branch of the YPL system was invited to participate by the SLC library director. Inclusion of YPL signified that YHS students would receive committed instructional support and access to the resources of all three libraries, a situation advantageous for anyone enrolled in a competitive precollege program. Prior to the partnership's implementation, a strategic planning committee comprised of key players from YPL, YHS, and SLC was formed to determine present and future financial, professional, and spatial requirements. Currently, the committee is comprised of SLC reference librarians, YHS IB teachers and the IB coordinator, and the YPL Head of Reference. In June 2011 the Media Specialist position was eliminated from YHS because of budget cuts and is now retired.

\section{PROGRAM PLANNING AND IMPLEMENTATION}

During the academic calendar year three major events are orchestrated by the planning committee on behalf of the YHS IB students. Organization of 
these gatherings is contingent upon effective and consistent contact between YHS, YPL, and SLC staff. The planning committee meets two to three weeks before an event at either SLC or YPL to create an event agenda and solidify logistical and content details. Minutes are taken during these meetings and are later sent via email to all committee members. This recordkeeping guarantees the committee an archive of past activities and instruction, providing a foundation from which to continuously construct a stronger program.

Shortly after beginning the fall semester, YHS IB juniors attend Junior Research Orientation Day, an event located at the YPL main library. The objective of this day is to acclimatize the students with print resources, the library catalog, and a couple of online databases. Students are assigned a broad research paper topic, which is generally "Slavery in the Americas," and from there they can focus their paper on any related subject matter of their choice. Orientation day is intended to assist students in locating sources to formulate their topic selection. Beginning at 9am and running until midafternoon, this event offers each student five separate 30- minute classes taught by SLC and YPL librarians. The classes include a YPL library tour, how to create a research strategy, usage of the online catalog, an introduction to databases, and information on the print reference collection. After the conclusion of the classes students are given an hour to explore the library's resources at their leisure and are required to provide their teachers with citations for one or two relevant resources at the end of the orientation.

The next event, Topic Day, occurs at SLC in January. By this time YHS students have selected a concrete topic for their research paper. The planning committee meets at SLC two to three weeks before Topic Day to finalize the agenda, which the students are given in print format on the day of the event. YHS students arrive at SLC at 9am and receive group instruction from SLC reference librarians on the library catalog, print reference collection, and databases. Students are given the majority of the afternoon to work independently on their own research in the computer lab and/or the stacks, with reference librarians available to assist. Throughout the day students are reminded that they are welcome to return to the library at any point during the hours the library is open to the community, and that they can borrow books from SLC through YPL's Interlibrary Loan service.

The third and final event in the partnership is particularly significant in terms of academic/high school collaborations: independent research consultations between YHS students and SLC reference librarians. A highlight of services offered to SLC students by the reference department, the one-onone research consultation is an especially effective method of instruction, as it can be carefully tailored to both the research interests and experience level of an individual library patron. Gale and Evans (2007) explain the benefits of one-on-one meetings:

Research consultations serve to fill the gap between traditional library instruction and reference desk services by providing individualized 
inquiry-based instruction. As a complement to an information literacy program, consultations provide an opportunity to ensure success for students who might fall through the cracks, as well as provide the best service possible for those with complex research needs. (p. 90)

In addition to assisting college-level patrons requiring additional or specialized research attention, consultations can serve as a flexible and singularized gateway to the academic library for high school students.

Occurring every March during SLC's spring break, the consultations for YHS students are divided between the three reference librarians over the course of three days. One-hour appointments are scheduled in advance and take place in the SLC reference office. The numbers of students participating in this juncture of the partnership is unfortunately much lower, as buses are provided for both previous events but students must arrange their own transportation for the consultations. Because the learning outcome of the consultations is for the students to create a bibliography on their paper topic, SLC librarians attempt to ensure that students are capable of locating a variety of library resources. Databases are discussed in greater detail than during Topic Day, particularly subject databases pertinent to students' research papers. Students are encouraged to contact the reference librarians to make additional research appointments in the future, although YHS students rarely take advantage of this opportunity.

After YHS students complete their spring semester the planning committee meets in late May or early June to debrief, recapping successes and brainstorming areas for improvement. At this meeting, the dates for next year's event calendar are tentatively set, with each event assigned an alternate date in case of inclement weather. The members of the committee also ensure to meet for

\begin{tabular}{|c|c|c|c|c|c|c|c|c|}
\hline & Oct & Nov & Dec & Jan & Feb & Mar & Apr & May \\
\hline \multicolumn{9}{|l|}{ Planning Meeting for Orientation } \\
\hline \multicolumn{9}{|l|}{ Day } \\
\hline \multicolumn{9}{|l|}{ Orientation Day } \\
\hline \multicolumn{9}{|l|}{ Planning Meeting for Topic Day } \\
\hline \multicolumn{9}{|l|}{ Topic Day } \\
\hline \multicolumn{9}{|l|}{ Planning Meeting for Consultations } \\
\hline \multicolumn{9}{|l|}{ Consultations } \\
\hline Annual Review & & & & & & & & \\
\hline
\end{tabular}

FIGURE 1 Program planning schedule. 
an annual gathering, usually held at a local restaurant. While other meetings 355 focus on logistics of the partnership, the purpose of this event is for the committee to socialize and celebrate the pleasant bonds formed over the years. Figure 1 shows the annual planning, implementation, and evaluation process.

\section{REWARDS}

The extensive nature of the program results in significant benefits for all groups involved, from institutional to individual levels. SLC is rewarded for its participation by demonstrating the value of the library to college administration and increasing visibility in the local community, as well as diversifying librarian skill sets. YHS benefits directly from the access to professional librarians and the college's collections. Finally, both institutions see the rewards of bridging the gap between high school and college-level research skills and contributing to a decrease in library anxiety.

Through its participation, SLC Library demonstrates to administrators and the community the library's educational value and involvement beyond the college's border. The associated visibility in the community can result in more significant outcomes than a simple acknowledgment. As Carlito (2009) states, "the university benefits because library outreach acts as a public relations tool" (p. 38). When asked about the benefits of participation in the program, the Director of Libraries and Academic Computing at SLC comments, "It allows us to build relations with our immediate community and helps to nurture young scholars" (S. Fagan, personal communication, May 15, 2012). The cumulative outcomes of demonstrating value, raising the library's profile, $\quad 380$ and building community relations are indeed extremely beneficial.

By working closely with high school students, reference librarians at SLC have the opportunity to diversify their skill sets and rework instruction sessions to meet the needs of younger learners. The process also helps the reference staff to consider assumptions made about student expectations and skill levels. Burhanna (2007) observes that through providing orientations for local high schools, the staff at Kent State University (KSU) "have learned that the culture of academic libraries is much different from that of school libraries and that part of their mission is to help students understand these differences" (p. 81). A related indirect benefit is the pleasure of working with highly motivated students. Burhanna and Jensen note this in their 2006 article, stating that "the students are engaged and enthused... they follow directions and work hard," in opposition to what many librarians providing instruction may encounter with their first year students (p. 514). Apart from having the pleasure of instructing students that pay a great deal of attention during classroom sessions, the students' desire to absorb information and obtain an edge on college life in turn encourages librarians to deliver instruction sessions that will further enhance their learning (Collins, 2009). 
The partnership was originally developed with the intent of providing high school students with access to resources at a small academic library. What is now perceived by YHS as the more significant benefit is having a connection to professional librarians whom lend a credence and academic slant to the library sessions. In the words of the former YHS media specialist, "Meeting with SLC librarians reinforces what we teach the students ... SLC librarians bring a scholarly approach that isn't always possible in a high school setting" (B. Hough, personal communication, May 21, 2012). Moreover, the reference librarians feel it is incumbent upon them to give students a positive experience while using the library, an attitude which reflects well upon both the institution and libraries in general.

Bridging the gap between high school and college-level research and information literacy skills is a goal central to this collaborative effort. Developing partnerships with K-12 instructors is advocated in the library literature as a means to help students make a successful transition from high school to college by equipping them with the abilities vital to meeting the demands of their freshman-level courses (Islam \& Murno, 2006). In particular, such programs allow students to understand the expectations of collegelevel information literacy skills. A teacher at YHS commented, "The students are so grateful and thankful for all the help they have received with the library services. The graduates feel that their skills have helped transition into college more easily" (M. Lentine, personal communication, May 19, 2012). While not every student who is part of the program proceeds to college with fully developed information literacy skills, the staff at SLC and YHS have witnessed major improvements made by students during the academic year spent working with them, making the process of bridging the gap between high school and college a gratifying experience.

By having high school students spend extended time actively using library resources in unfamiliar public and academic settings and speaking to reference librarians one on one about their research, the program also has the effect of decreasing students' library anxiety. High school students are often encouraged by their teachers to visit academic libraries in order to become more familiar with a library environment that is frequently far more complex than what they experience in their high school's library. This increased familiarity can in turn lead to a decrease in library anxiety felt by students once they are required to use an academic library, whether while still in high school or as a new college student. It is well documented that students feel intimidated by academic libraries (Mellon, 1986), and exposure to this potentially overwhelming setting through instruction or an orientation can be extremely useful in encouraging effective use of the library later in their academic careers. A key factor in decreasing library anxiety is giving students individualized attention so that they are able to ask questions when they feel lost or confused by the complexities of a library, which the program addresses via individualized research consultations and ample one-on-one time during orientations. 
There are challenges inherent in any collaborative project of this size and scope. Evans (1997) notes some of these drawbacks and reasons why such a project might pose difficulties, including drawing from time and resources spent on current students, the instruction sessions disturbing current students, and the activities not necessarily being rewarded by administrators. Moreover, the literature on collaborative programs between academic libraries and other institutions tends to focus on positive outcomes almost exclusively, to the detriment of presenting challenges to consider before undertaking a partnership with a local high school. At SLC four primary issues have been identified, including time spent by reference librarians, coordinating the substantial number of professionals involved in administering the program, formally evaluating the partnership, and potentially drawing from time spent with our primary campus constituents.

As is the case in any academic library, staff time is a valuable commodity and must be considered carefully before committing to additional responsibilities. Participating in the program with YHS and YPL requires an estimated annual 40 hours of staff time for each of the three reference librarians at SLC; this is not an insubstantial commitment. Burhanna (2007) noted that librarians at KSU typically devote six hours to high school visits, whereas instructional engagements with KSU students rarely take more than four hours. Understanding expectations of time spent and identifying points in the academic year that are less demanding are highly useful steps to take. For instance, planning meetings at SLC are held before the fall semester starts, the library orientation takes place during the college's winter break, 465 and consultations take place during the week of spring break.

With a program administered by as many as ten professionals representing three different institutions, coordination between participants can present a major difficulty. When asked what challenges the IB Program faces, a teacher at YHS simply answers, "Logistics—scheduling and transportation concerns" (M. Lentine, personal communication, May 19, 2012). Apart from aligning schedules to find times for program planning, for instructional sessions and consultations to occur, and an annual evaluation, the teachers at YHS have additional coordination responsibilities that include their students' transportation and lunch needs. Complicating these demands is the fact that the YHS media specialist retired last year due to unreasonable work expectations. As the Head of YPL's Reference Department states, "Our biggest challenge has been losing the YHS librarian - she was the liaison between all of the partners. Now we don't have a clear cut leader. She kept us on track and created a very organized planning schedule" (A. Cruz, personal communication, May 19, 2012). We recently found that by identifying one contact in each institution who is responsible for representing the IB program, communication has become less of a challenge in the wake of this unfortunate 
departure. Nonetheless, academic librarians can anticipate that coordinating a large-scale program such as this will require patience and perseverance.

Assessing a program of this type may present difficulties for librarians in institutions that lack a pre-existing culture of assessment. In the case of the IB program partnership, measuring student outcomes was not initially considered, and an annual review conducted among the three participating institutions had sufficed in terms of determining the program's progression. However, it is difficult to demonstrate value to administrators when there is no assessment component. While SLC Library is fortunate to have the support of college administration and does not have a pressing need for assessment, other institutions may find their environment to differ greatly and require assessment measures from the onset. Anecdotal evidence of student satisfaction and college success is useful but having data on the number of program participants, percentage of college or university matriculation, and pre- and posttests to gauge student knowledge retention are greater proof of the program's value. Though challenging to do so, creating a formal evaluation of a new program is important to identifying its successes or shortcomings.

A fourth challenge faced is the question of whether participating in the program detracts from time or assistance that can be spent on primary constituents such as current students, faculty, and staff. Although this factor will vary by institution, SLC has found the program does not interfere with services to our campus. This is due in part to the scheduling that allows for the days of in-depth contact with high school students to occur during college breaks. Other libraries may find their situation to differ. The question of whether primary users needs are going unmet or are being interfered with due to program involvement is imperative, and should be asked on a frequent basis. It should be considered along with time expectations and the potential benefits of collaborating with a local high school.

From these challenges come lessons and insights into developing a partnership that made our program a success. Rewards and challenges can be identified, but how does an institution know whether a program is right? Based on our experiences we have developed several questions to help academic librarians determine the applicability of a high school partnership to their own setting.

\section{LOCAL APPLICABILITY}

The value of a collaboration with local high schools to teach students information literacy skills will vary widely by institution. The steps that libraries take to initiate a program or carry out instruction for students depend on a host of factors and, as such, the need and reasons for developing a partnership should be carefully considered before further action is taken. To help libraries determine the local applicability of such a program, several key 
questions designed for laying the groundwork of a successful collaborative 525 effort are presented, including institutional type and mission, identifying desired outcomes, evaluating the levels of different resources necessary for supporting additional library users, and considering whether there is a demonstrated need.

An institution's public or private status can to a large extent determine whether an information literacy outreach program for high school students is appropriate. Institutions that receive funding support from their state are frequently required to provide public access to their resources. Naturally, high school students are thus given access to some library and campus amenities, and the case can easily be made for additional outreach and resources for this group of learners if there is a documented interest. At KSU, for example, the state-supported university "has an obligation to the citizenry of Ohio and recognizes the value in good community relations" and participates in an intensive high school outreach program (Burhanna, 2007, p. 82). Private institutions, on the other hand, may not feel a pressing need to engage their community, and indeed are not expected to. Though not required, it should be noted that private institutions may reap the same benefits of a collaborative program and feel such outreach is worth the effort on its own accord, as is the case at SLC.

Consider whether a program for high school students is in line with your institutional and library mission statements. An endorsement of community outreach stated in institutional policy demonstrates an organizational commitment to these same ideals. Consult your institution's mission, the library's mission if applicable, and identify whether community outreach is mentioned. If these documents lack such verbiage, it is possible that such programming is not considered by your institution to be a primary concern and efforts may be better spent on services for the campus community. Also take the time to consider potential partners' missions and potential organizational interest. The Head of Reference at YPL advocates that in the planning stages of a partnership, "Do your research before you meet with potential partners ... show them how a partnership would tie into their mission" (A. Cruz, personal communication, May 19, 2012). A statement in an institution's mission regarding community engagement can provide the solid backing necessary for a partnership to thrive.

Identifying desired programmatic outcomes is a crucial step in considering the local applicability of an information literacy program for high school students. Discussing outcomes makes what may be a vague notion of an initiative into a more tangible project. The outcomes can be brought to potential partners as a way to show shared pedagogical ground and clarify expectations. Additionally, outcomes will demonstrate to administration that the goals of the program have been made concrete and can be achieved. Questions central to visualizing the program and its applicability in your library include: 
What does our home institution expect to receive from participating in such a program? What should the outreach program look like in five years? What change do we hope to see in high school students' information literacy levels? How will we measure the program's success? With several outcomes having been selected, your institution will be in a position to assess whether the outreach and instruction is meeting the needs of all partners and participants.

It is vital to evaluate whether your institution has the necessary resources to pilot and sustain a project of the scope you are considering. The resources involved in an instruction program for high school students includes a number of assets, including librarian time, collections, and physical space. Large libraries are more likely to have the benefit of a larger reference and instruction staff to draw upon, more substantial collections to provide students, and additional classrooms in which to provide instruction sessions. Despite these potential advantages of large libraries, these same issues may be met even in a small college setting. The partnership at SLC is based upon a full-time reference staff of three. Between scheduling sessions during the times most convenient for the librarians and our campus, determining that use of the physical collection is allowed only on site, and blocking out days for our exclusive use of the library's electronic classrooms, we are able to meet the needs of both our local on-campus community and our extended community of high school learners. While it can be challenging to measure the numerous demands a new program will place on staff time and library spaces and collections, it is highly beneficial to attempt to interpret these requirements in advance to see if a program for high school students is feasible.

Most importantly, ask whether there is a need originating from local high school students or other users outside your institution. If your library receives significant contact from high school students without having established an outreach program, it may signify that a partnership with local schools would be highly beneficial. Conversely, if your institution rarely receives inquiries from high school teachers or visits from local students, the value of delivering instruction to this population may be of lesser importance than other activities. The SLC Library Director advises institutions that are considering implementing an outreach program to "learn what the local needs are, and not to push a program on the community ... exploratory conversations with key players need to occur; not every community would have the need for this partnership" (S. Fagan, personal communication, May 15, 2012). This advice is echoed by Jackson and Hansen (2006). User needs being the foundation for the ways in which library services are delivered, considering whether there are existing needs for a partnership is of paramount importance.

After considering these questions related to local applicability and deciding whether an instructional program for high school students would 
be valuable enough to offset the challenges and demands, it is helpful to be aware of best practices as documented by other institutions. Each library must make the decision of whether a program is right for its staff, institution, and greater community, and by examining best practices others can benefit from the accrued knowledge of experienced participants.

\section{BEST PRACTICES}

Through eight years of experience managing the outreach and instruction program, interviews with colleagues in each of the three partner institutions, and a review of the LIS literature, several best practices for a similar initiative have been identified. While not obligatory, these recommendations will improve the probability of a successful long-term initiative: pilot the program, designate a contact person in each institution, conduct an annual review, and determine ways to defend your program in advance.

As with any initiative that seeks to engage additional users and is produced in conjunction with other institutions, it is highly recommended to pilot the program for a predetermined length of time before fully committing. Planning and executing the program for even one semester will allow your institution to see firsthand any demand on facilities, collections, and librarians' time resulting from your participation. It will also give you experience conducting the program that is necessary for adjusting the program to better suit the needs of your library. Subsequent to piloting the program, even if it is decided that the program is infeasible as it exists, alterations can be discussed and implemented with little difficulty.

Having a designated point person in each institution is vital to keeping the partnership free of unnecessary confusion. No more than one person representing each institution is needed, as the goal is to simplify communications rather than complicate what is already an elaborate system. The Head of Reference at YPL recommends to "know who the key person in the building is" and to make that person the contact (A. Cruz, personal communication, May 19, 2012). Beyond making the process of emailing and scheduling more manageable, the community will also have central contact in each institution to answer questions or requests related to the program. With the partnership at SLC, coordinating a group of ten professionals has become much easier after the assignment of designated point persons.

Conducting an annual review is an ideal way to take stock of and make improvements to an instructional outreach program. In particular, an annual review allows for all stakeholders to express their views on what works and what does not, as well as identify ways to address concerns. It also provides an excellent opportunity to celebrate successes of the program and reflect upon the achievements of students who have since graduated from high school. The annual program review at SLC is typically preceded by a brief 
agenda emailed to all attendees in advance, which includes such points for discussion as scheduling, brainstorming for improvements to be made, and catching up with developments at each other's organizations.

With many colleges and universities facing continuing financial challenges, it is unfortunate but imperative that plans for defending the value of new programming are made even before a new initiative is underway. Obstacles to assessment, while considerable, must be overcome to demonstrate the value of the program. Options for defending the program can include such things as anecdotal evidence of student, teacher, and media specialist satisfaction with the program's process and outcomes, and collecting statistics on number of high school students reached and percentage of college or university matriculation ensuing participation in the program. At SLC we are in the process of developing an informational online video regarding the partnership, which will include interviews with teachers and students, clips of orientation sessions and individual consultations in progress, and other indicators of the program's success and value to students seeking to attain their educational goals. The video will be shared with those interested in the program, and apart from its promotional value, can serve as a defense of the partnership.

The preceding best practices and questions to ask regarding local applicability will help academic librarians determine if an instruction program for high school students is right for their institution. Whether or not a program for is appropriate, we encourage librarians to begin a dialogue with local high school media specialists and to network with other academic libraries providing programming for high school students. Sharing information about student needs and their skill levels and expectations precollege and postcollege enrollment will benefit students and librarians alike.

\section{CONCLUSION}

For nearly a decade, the partnership has provided young members of the community with the tools and instruction needed to locate, evaluate, and apply information advancing both themselves and the world. YHS students and teachers alike frequently verbalize the value and utility of the program, as evidenced by positive feedback of program participants throughout this article.

Due to the dearth of information in LIS literature on similar partnerships, additional research is crucial to the maintenance and future development of secondary school, public library, and academic library collaborations. For example, the development of a pretest and posttest survey to assess the impact of library instruction on high school students would be one method of concretely evaluating the partnership's successes and failures. Each student could be given a brief quiz surveying his or her knowledge of 
basic library research in September before receiving any instruction. The same quiz could be administered at the end of the school year and analyzed against the results from the first test. Demonstrated improvements detected over the course of the year could be attributed, at least in part, to the efforts of the partnership.

Additionally, it would be beneficial to see more scholarship that focuses on academic and/or media center library instruction directed at high school students in the IB program. Currently the IB Diploma Programme is offered by 1,232 high schools worldwide (International Baccalaureate, n.d.b). This high number of IB programs implies the need for the creation of coexisting local partnerships with academic and public libraries, as research has already indicated that the IB curriculum requires the usage of library resources extending beyond the purview of the traditional school media center. It is the hope of the authors of this article that the SLC/YPL/YHS partnership serves as a model for other academic libraries wishing to support the complex research needs of IB students located within their geographical areas. The overall goal of this type of partnership is best explicated by Carr and Rockman (2003), as they write, "only by collaborating to ensure a curriculum rich in information literacy for all students at all levels can we have a society that is prepared to recognize the value and need for information in a democratic society." (p. 54).

\section{REFERENCES}

Adeyemon, E. (2009). Integrating digital literacies into outreach services for underserved youth populations. Reference Librarian, 50(1), 85-98.

Association of College \& Research Libraries. (2000). Information literacy competency standards for bigher education. Chicago, IL: American Library Association.

Brody, B. (2012, February 27). High-achieving students from the Yonkers school district Westchester Magazine. Retrieved from http://www.westchestermagazine. com/Westchester-Magazine/December-2011/High-Achieving-Studentsfrom-the-Yonkers-School-District

Bruch, C., \& Frank, K. (2011). Sustainable collaborations: Libraries link dual-credit programs to P-20 initiatives. Collaborative Librarianship, 3(2), 90-97.

Burhanna, K. J. (2007). Instructional outreach to schools: Should you be doing it Communications in Information Literacy, 1(2), 74-88.

Burhanna, K. J., \& Jensen, M. (2006). Collaborations for success: High school to college transitions. Reference Services Review, 34(4), 509-519.

Carlito, D. (2009). Urban academic library outreach to secondary school students and teachers. Urban Library Journal, 15(2), 35-49.

Carr, J. A., \& Rockman, I. F. (2003). Information-literacy collaboration: A shared responsibility. American Libraries, 34, 52-54.

Collins, B. L. (2009). Integrating information literacy skills into academic summer programs for precollege students. Reference Services Review, 37(2), 143-154. 
Cosgrove, J. A. (2001). Promoting higher education: (Yet) another goal of biblio740 graphic instruction of high school students by college librarians. College $\mathcal{E}$ Undergraduate Libraries, 8(2), 17-24.

Evans, B. (1997). Building bridges between New York City public high school and a college: The cooperative library project. Research Strategies, 15(2), 89-99.

Gale, C. D., \& Evans, B. S. (2007). Face-to-face: The implementation and analysis of 745 a research consultation service. College \& Undergraduate Libraries, 14(3), 85-101.

International Baccalaureate. (n. d.a). Yonkers Middle/High School. Retrieved from http://www.ibo.org/school/001282

International Baccalaureate. (n. d.b). IB Americas. Retrieved from http://www.ibo. org/iba/index.cfm

Islam, R., \& Murno, L. A. (2006). From perceptions to connections: Informing information literacy planning in academic libraries through examination of high school library media center curricula. College \& Research Libraries, 67(6), 491514.

Jackson, L., \& Hansen, J. (2006). Creating collaborative partnerships: Building the framework. Reference Services Review, 34(4), 575-588.

Jamelske, E. (2009). Measuring the impact of a university first-year experience program on student GPA and retention. Higher Education, 57(3), 373-391.

Lee, J., Morris, B., Brazell, B., \& Turner, J. (2007). Information literacy collaboration: A shared responsibility. Colorado Libraries, 33(3), 5-10.

Mellon, C. A. (1986). Library anxiety: A grounded theory and its development. College E Research Libraries, 47(2), 161-165.

Schein, C., Conway, L., Harner, R., Byerley, S., \& Harper, S. (2011). Bridging the gap: Preparing high school students for college level research. Colorado Libraries, 36(1),(1-4.) Seidman, A. (2005). College student retention: Formula for student success. Westport, CT: Praeger.

Tilke, A. (2011). International Baccalaureate Diploma Programme: What it means to a school library and librarian. School Library Montbly, 27(5), 8-10.

U.S. News \& World Report. (2012). Yonkers middle high school overview. Retrieved 770 from http://www.usnews.com/education/best-high-schools/new-york/districts/ yonkers-city-school-district/yonkers-middle-high-school-14199

Wilcox, P., Winn, S., \& Fyvie-Gauld, M. (2005). "It was nothing to do with the university, it was just the people": The role of social support in the first-year experience of higher education. Studies in Higher Education, 30(6), 707-722.

Yutzey, S. D., \& Piazza, L. M. (2007). The International Baccalaureate Programme and the school librarian. Obio Media Spectrum, 59(1), 23-28.

Zoellner, K., \& Potter, C. (2010). Libraries across the education continuum: Relationships between library services at the University of Montana and regional high schools. Behavioral \& Social Sciences Librarian, 29(3), 184-206. 